\title{
A FILOSOFIA NA PERSISTENNCIA DE SUA TRADIÇÃO DIALÉTICA
}

\author{
Douglas Garcia Alves Júnior* \\ dougarcia@rocketmail.com
}

\section{DUARTE, Rodrigo. Dizer o que não se deixa dizer: para uma filosofia da expressão. Chapecó: Argos, 2008.}

Os seis ensaios do mais recente livro de Rodrigo Duarte - nome que se confunde com a recepção de Theodor W. Adorno no Brasil — apresentam aos leitores um exercício de reflexão sobre o lugar da dialética no horizonte filosófico contemporâneo. Trata-se de explicitar a atualidade do conceito da dialética, em sua versão adorniana, a dialética negativa, na qual a atenção ao não idêntico e ao singular é aliada à busca da decifração do movimento identitário de totalização econômica, cultural e social, que é realizado pelo capitalismo em sua configuração tardia. Nesse sentido, esses ensaios estéticos recobrem uma dupla significação: reafirmam a centralidade do momento linguístico, composicional, no interior do discurso filosófico, e, por outro lado, apontam para a centralidade da estética filosófica no trabalho de prospecção dos impasses da racionalidade contemporânea.

Uma tese forte percorre esses ensaios: toda filosofia é expressão, mesmo aquelas versões do discurso filosófico contemporâneo mais refratárias à ideia de uma dimensão retórica da filosofia. Assumir essa dimensão expressiva da filosofia é apontar para a necessidade de reflexão do seu elemento mimético, que, na filosofia, se dá no nível da construção da linguagem — por isso tem sentido falar, com Adorno, de "retórica", aqui. Isso porque a dialética negativa é um esforço incessante de registrar a experiência da não identidade de conceito e coisa no discurso filosófico. Não se trata de abandonar o conceito em nome

* Professor Adjunto do Departamento de Filosofia da UFOP.

KRITERION, Belo Horizonte, nº 119, Jun./2009, p. 269-274. 
de uma pretensa dimensão originária - miragem que a dialética negativa não se cansa de denunciar, seja o seu nome a Natureza, o Ser, a Linguagem mas de persistir com o conceito para fazê-lo dizer o que não se deixa dizer ${ }^{1}$ tão somente por meio de sua configuração ordinária, que toma o conceito como correspondência direta da coisa por ele visada.

Fazer a defesa de uma filosofia da expressão, portanto, é o que Duarte propõe, no espírito de Adorno e da dialética negativa. Espírito que poderia ser descrito como a tentativa de pensar uma forma de racionalidade ancorada numa intersubjetividade (como Habermas, que afirma o primado de uma razão situada nas formas linguísticas geradas a partir da autorreflexividade social moderna), que se articula (à diferença de Habermas) como campo de forças constituído pelas relações sociais de dominação da natureza externa e interna.

A menção à questão da intersubjetividade e à dominação social da natureza, ambas inscritas como fundamentos da razão, na perspectiva da dialética adorniana, não é gratuita. Com ela, pretendo apontar para uma continuidade que atravessa os trabalhos centrais de Duarte sobre Adorno, desde Mímesis e racionalidade: a concepção de domínio da natureza em Theodor W. Adorno (Loyola, 1993), passando por Adornos: nove ensaios sobre o filósofo frankfurtiano (Ed. UFMG, 1997), até seu mais recente Deixar o que não se deixa dizer: para uma filosofia da expressão (Argos, 2008).

No primeiro livro, resultado de sua tese de doutorado, defendida em Kassel, tratava-se de discernir o núcleo de uma sistematicidade da obra de Adorno, dado pela ideia de uma contraposição possível, no domínio da filosofia - e de seu elemento, a expressão da contradição objetiva entre razão e natureza - , ao processo de dominação da natureza levado a cabo por uma versão antirreflexiva (e, portanto, não dialética) de racionalidade, vigente na modernidade. ${ }^{2}$

Em Adornos, Duarte persegue, por meio do ensaio, o movimento constitutivo da filosofia de Adorno, feito da composição de suas múltiplas facetas, das quais ele ressalta o diálogo com a arte (especialmente a música), com a tradição filosófica (notadamente Marx e Hegel) e com a experiência histórica de seu tempo (nesse registro, os ensaios sobre Minima Moralia e sobre a escrita ensaística de Adorno são exemplares). Por fim, mas não menos 
importante, comparecem dois trabalhos de Duarte que se inscrevem plenamente neste fio vermelho proporcionado pelo debate em torno da temática da expressão. Trata-se dos ensaios: "Notas sobre a 'carência de fundamentação' na filosofia de Theodor W. Adorno" e "Expressão como fundamentação".

Neles, contrapõe-se uma alternativa dialética à interpretação da obra de Adorno feita por Habermas, a qual alcançou grande influência a partir da publicação de $O$ discurso filosófico da modernidade (1985). Com efeito, no intuito de situar polemicamente os fundamentos de sua Teoria da Ação Comunicativa, Habermas havia enquadrado Adorno e Horkheimer no papel de representantes de um pensamento sem saída, preso nas malhas da filosofia da consciência, incapaz de enxergar diferença entre poder e validade, que teria totalizado o diagnóstico da razão moderna como razão instrumental - pensamento que, assim, teria caído na situação aporética da contradição performativa. ${ }^{3}$ Habermas propunha, ali, substituir o trabalho como categoria central da práxis, em favor da ação comunicativa. ${ }^{4}$ A "situação ideal de fala" seria o horizonte normativo capaz de vincular a fundamentação de pretensões de validade surgidas numa argumentação, de modo a constituir o universo autorreflexivo de uma razão comunicativa. ${ }^{5}$

Duarte, nos dois ensaios acima indicados, não só expõe o caráter restritivo das críticas de Habermas a Adorno - ao mostrar que Adorno problematiza a pretensão de totalidade da crítica da razão ${ }^{6}$ - como aponta para um modo de fundamentação filosófica das pretensões de validade que pode ser constituído a partir da concepção adorniana de razão, à qual o conceito de expressão se vincula. Trata-se, segundo Duarte, de mostrar que:

O elemento transcendental que está na base da atitude "prática" do ser humano não é a "competência comunicativa", mas algo que lhe antecede, um desejo — racionalmente mediado - de que tudo seja diferente do que é, o qual pode-se denominar "impulso emancipatório", sendo a capacidade da linguagem apenas epifenômeno seu. ${ }^{7}$

3 Cf. HABERMAS, Jürgen. O discurso filosófico da modernidade: doze lições. Tradução de Luiz Reppa e Rodnei Nascimento. São Paulo: Martins Fontes, 2002. Cito: "Fica inalterada a figura de pensamento em que se insere o ceticismo diante da razão: agora é a própria razão que suspeita da funesta confusão de pretensões de poder e pretensões de validade... Esta descreve, contudo, a autodestruição da capacidade crítica de modo paradoxal, visto que no instante da descrição ainda tem que fazer uso da crítica que declarou morta. Ela denuncia o esclarecimento que se tornou totalitário com os meios do próprio esclarecimento. Adorno estava perfeitamente consciente dessa contradição performativa da crítica totalizada" (p. 170).

4 Cf. O discurso filosófico da modernidade, p. 440 et seq.

5 Cf. Idem, 449 et seq.

6 Cf. Notas sobre a "carência de fundamentação" na filosofia de Theodor W. Adorno. In: Adornos: nove ensaios sobre o filósofo frankfurtiano, p. 137 et seq.

7 Idem, p. 138. 
Cuida-se, assim, de pensar em um conceito de razão mediado por um impulso de libertar-se da coerção que pesa sobre os seres humanos, na medida em que estes se põem como artífices (e vítimas) de um processo universal de dominação da natureza, processo fundado numa categoria obliterada por Habermas, a de trabalho social. ${ }^{8}$

Os ensaios de Dizer o que não se deixa dizer retomam essa problemática, reunindo trabalhos publicados em diversos periódicos, a partir do final dos anos 1990, além de alguns inéditos.

Dois dos ensaios exploram a fecundidade do conceito de expressão, pensado como fundamento de uma racionalidade dialética, na interlocução da filosofia com domínios culturais que lhe são exteriores, a saber, a psicanálise, em "Sublimação ou expressão? Um debate sobre arte e psicanálise a partir de T. W. Adorno", e a música, em "O conceito de expressão de Adorno e a relação entre a música e a filosofia".

Do diálogo com a psicanálise, Duarte aborda, sobretudo, a insuficiência do conceito de sublimação para a interpretação das obras de arte, em virtude da centralidade da lei formal estética para a construção da obra. Além disso, tratase de caracterizar a relação entre obra e vida pulsional por meio do conceito de expressão, aparência estética racionalmente mediada, que nega a realidade constituída, explicitando um conflito objetivo entre sujeito e sociedade.

Da reflexão sobre a relação entre música e filosofia, Duarte propõe pensar o conceito de expressão do sofrimento humano, como elemento transubjetivo fundamental do conhecimento, em que se encontraria latente uma linguagem ainda não subjetiva, ainda não humana - nesse caso, a música não seria mimésis de sentimentos determinados, mas da condição humana de um modo geral, no que ela tem de desamparo diante da linguagem e da violência social.

Em "O conceito de linguagem de Benjamin e a Teoria Estética de Adorno", Duarte contribui para o esclarecimento dos laços significativos entre o pensamento estético dos dois filósofos, frequentemente tomados, em nosso país, como representantes de uma série de oposições abstratas. Não é o caso de Duarte, que mostra como o conceito de linguagem do jovem Benjamin, marcado pela ideia de expressão da essência espiritual das coisas e dos homens, permite a Adorno pensar em uma dimensão expressiva da linguagem, para além da mera comunicação — dimensão fundamental à arte, "símbolo do que não é comunicável", nas palavras de Benjamin. ${ }^{9}$ 
Os demais ensaios tematizam o conceito de expressão de Adorno, em suas diversas facetas. Em "Expressão estética: conceito e desdobramentos", Duarte reconstitui sua linhagem filosófica, a partir da estética de Hegel, que desenvolveu uma crítica da ideia de arte como mimésis, bem como a explicitação de seu caráter histórico; de Véron, que associou o conceito de expressão à manifestação da subjetividade; de Santayana, que ressaltou o seu elemento relacional; e, finalmente, remete ao conceito de expressão de Benedetto Croce, que o associou à inspiração e à intuição.

Os ensaios "Expressão como atitude filosófica", que abre o livro, e "A dialética como liberdade de expressão" situam com acuidade o alcance dialético do conceito adorniano de expressão. No primeiro, Duarte alcança, talvez, o maior equilíbrio, dentre todos os textos da coletânea, entre a forma e o conteúdo da exposição filosófica, mostrando a atualidade da expressão para a filosofia, na assunção do trabalho com a contradição objetiva, que não se dissolve em sistemas funcionais de pensamento. Aqui ele retoma a controvérsia com a interpretação habermasiana de Adorno, iniciada já nos textos de Adornos, para aprofundar o seu nervo vital, qual seja, o desmonte da ideia de que somente a racionalidade voltada para o entendimento recíproco poderia salvar uma concepção de razão que abarcasse a estrutura fundamental da intersubjetividade. Duarte mostra que a experiência estética fornece a indicação para o pensamento filosófico, de que é preciso persistir na indissolubilidade da contradição entre razão e naturalidade, reconhecendo, em cada manifestação do pensamento, a força da dominação da natureza. É nesse sentido que a filosofia assume o caráter de interpretação dos traços, às vezes ilegíveis, que a dominação imprimiu no material histórico, no registro do estético, assumindo, assim, um alcance ético, de emancipação do gênero humano.

Em “A dialética como liberdade de expressão", Duarte examina as noções do primeiro Wittgenstein, segundo as quais a proposição lógica é uma figuração de estados de coisas, e de que à filosofia cabe o esclarecimento da linguagem, isto é, "o método correto da filosofia seria de fato esse: nada dizer, a não ser o que possa ser dito, isto é, proposições da ciência natural". ${ }^{10}$ Dessa proposição, segundo Wittgenstein, segue-se que "daquilo que não se pode falar, deve-se calar". ${ }^{11}$ Esse âmbito do qual a filosofia supostamente não poderia fornecer um discurso articulado seria o das questões éticas e metafísicas. A seguir, Duarte

10 WITTGENSTEIN, L. Tractatus logico-philosophicus, proposição 6.53. Apud DUARTE. Dizer o que não se deixa dizer, p. 66.

11 Idem, proposição 7, apud DUARTE. Dizer o que não se deixa dizer, p. 67. 
examina a filosofia de Karl Otto Apel, notadamente o seu Transformação da filosofia, para ressaltar a crítica de Apel ao projeto wittgensteiniano, no que ele arrisca de perder tanto a dimensão de reflexividade do sujeito quanto a dimensão hermenêutica da linguagem. Duarte assinala, contudo, a autolimitação em que Apel incorre, com seu programa de uma ética do agir comunicativo. A dialética negativa, de Adorno, é indicada como alternativa a essa deflação da consciência filosófica quanto à dimensão dialética da linguagem, proposta que assume como tarefa filosófica central, nos dizeres de Adorno:

com os meios do conceito dizer aquilo que, com os meios do conceito, não se deixa dizer. Isso é apenas possível pelo médium da linguagem, que faculta, simultaneamente fixar os conceitos e também modificá-los através do valor relativo que ela lhes atribui. $^{12}$

Trata-se, reafirma-o Adorno, de assumir que a filosofia é o "esforço de dizer daquilo que não se pode falar; ajudar a trazer o não idêntico à expressão, enquanto a expressão sempre o identifica". ${ }^{13}$ Nesse sentido, trata-se de trazer ao discurso filosófico as questões que ultrapassam o âmbito das ciências naturais, as questões de sentido, próprias de uma hermenêutica da subjetividade que se enraíza na esfera material, do corpo e das pulsões, campo de forças que é mediado pelas relações sociais de produção e pela relação dialética de razão e natureza. A expressão diz respeito, lembra Duarte, não a um sujeito individual, mas à humanidade como um todo. Assim, a dimensão performativa da linguagem, e a de toda filosofia, é reencontrada, de uma outra perspectiva que não a de Wittgenstein ou de Apel, mais afeita à dialética: a dimensão expressiva do discurso filosófico sempre move os seus interlocutores a tomar uma posição diante das rupturas históricas que os arranjos da razão introduzem na experiência social.

12 ADORNO, Theodor W. Philosophische Terminologie I. Frankfurt am Main: Suhrkamp, 1989. p. 56.

13 ADORNO, Theodor W. Drei Studien zu Hegel. In: Gesammelte Schriften 5. Frankfurt am Main: Suhrkamp, 1987. p. 94. 